FARZANA AFRIDI*

Indian Statistical Institute, New Delhi

VEGARD IVERSENं

University of Manchester, $U K$

\title{
Social Audits and MGNREGA Delivery: Lessons from Andhra Pradesh
}

\begin{abstract}
Using unique panel data assembled from official reports, we study the impact of social audits on Mahatma Gandhi National Rural Employment Guarantee Act delivery in Andhra Pradesh. Within a dynamic framework where beneficiaries, auditors, and transgressors interact and learn, we find a positive but insignificant impact of audits on employment generation and a modest decline in the leakage amount per labor-related irregularity: outcomes with high beneficiary stakes. This occurs alongside an increase in material-related irregularities with lower beneficiary stakes. Although we find evidence suggestive of beneficiary "learning" and of audit effectiveness in detecting irregularities, repeated audits did not deter irregularities. This highlights the need for a time-bound process where transgressors are punished and responsibilities for follow-up of social audit findings laid out and credibly enforced.
\end{abstract}

Keywords: MGNREGA, NREGS, NREGA, Social Audits, Corruption

JEL Classification: $H 4, I 3$

\footnotetext{
*fafridi@isid.ac.in

†vegard.iversen@manchester.ac.uk
}

The authors would like to thank the Government of Andhra Pradesh, particularly R. Subrahmanyam and Sowmya Kidambi for fruitful discussions and for facilitating access to the social audit reports. We are indebted to Devesh Kapur, Dilip Mookherjee, and to other IPF participants for incisive comments and Yamini Aiyar, Neelakshi Mann, Tom Newton-Lewis, and Jyotsna Puri for thoughtful remarks. This paper has also benefitted from comments by participants at 3ie's Delhi seminar, IGC South Asia conference (Lahore), and an NREGA conference at IGIDR, Mumbai. Swati Sharma provided excellent research assistance. The authors acknowledge financial support from the International Growth Centre (IGC, LSEOxford), No-POOR (European Union), and the Planning and Policy Research Unit (PPRU) at the ISI, Delhi. The usual disclaimers apply. 


\section{Introduction}

n spite of mixed experiences (e.g., Adato et al. 2005; Mansuri and Rao 2013), people's participation and social accountability (e.g., Joshi and Houtzager 2012) as mechanisms to foster transparency and improve public program delivery in developing countries are, once more, in vogue. In the public work projects implemented under India's largest program to date, the Mahatma Gandhi National Rural Employment Guarantee Act (MGNREGA; Government of India 2005), "social" audits have been made mandatory. The responsibility for audit implementation is vested with gram sabhas (p. 9, Section 17, I and II of the Act), which are plenary meetings of adult residents of gram panchayats (GPs) (village councils). The Act thus empowers intended beneficiaries to scrutinize program expenditures and to monitor and keep track of program delivery. ${ }^{1}$

Without sufficient institutional support, however, the expectation that beneficiary-led audits should spontaneously arise is unsustainable. Inspired by the civil rights movement spearheaded by the Mazdoor Kisan Shakti Sangathan (MKSS) ${ }^{2}$ in Rajasthan and other similar initiatives, the state government of Andhra Pradesh (AP) responded swiftly to this weakness in the Act (Aiyar et al. 2013). The early establishment of a pilot audit scheme was followed by the first steps toward a full institutionalization of the social audit process in the state (ibid.). By November 2007, social audits had been implemented in 400 of AP's 650 MGNREGA Phase-I sub-districts, a record no other Indian state can match (Aakella and Kidambi 2007). ${ }^{3}$

The AP social audit model is perceived as successful both within and beyond India's borders (Subbarao et al. 2013). The scaling up of this model to other Indian states makes it pertinent to distil lessons about what these affordable audits have been able to achieve so far. ${ }^{4}$ To the best of our knowledge, this is the first attempt to rigorously assess the impacts of a

1. In a study of Food for Work Programs in three districts of AP, predating MGNREGA, Deshingkhar and Johnson (2003) highlight the democratic deficiencies of gram sabhas.

2. Translated into English, MKSS is short for the Association for the Empowerment of Workers and Peasants.

3. This first phase implementation of MGNREGA started in February 2006 and targeted the 200 poorest districts in the country.

4. The cost of social audit implementation in AP has been low, absorbing between 0.5 and $1 \%$ of annual MGNREGA expenditure. The Ministry of Rural Development, Government of India, issued a circular to all state governments in 2012 earmarking up to $1 \%$ of annual MGNREGA expenditure for social audits. 
large-scale community monitoring initiative in India. By highlighting the strengths and shortfalls of AP's unique social audit experience, our aim is to improve effectiveness of community monitoring in AP and elsewhere.

The ideal design for identifying the causal effect of social audits on program delivery would be to randomize social audit implementation. Since the social audits in AP were not rolled out randomly, districts where social audits were conducted early may have had more (or fewer) program failures than districts audited later on. Comparing MGNREGA outcomes between early and late social audit recipients could therefore distort estimates of audit impacts.

In this paper we adopt the next best strategy by resorting to a panel data set assembled through meticulous extraction and translation of information from original social audit reports. The panel covers the years 2006-10 and comprises official data from up to three rounds of social audits from an initial sample of 300 GPs in eight districts of AP. Our analysis focuses on whether program performance measured by irregularities in program implementation - the immediate concern of social audits as well as employment and program expenditures - is affected by additional audits within the same sub-district over time.

Among these performance indicators, we prioritize outcomes that relate directly to malpractices and irregularities that speak to widespread concerns about leakages and corruption in large public programs in India. ${ }^{5}$ In addition, data on the local bureaucracy and elected panchayats enable us to assess the interaction between local government characteristics and program leakages which is crucial for improving public program delivery. We control trends that could potentially impact the quality of program delivery and corruption: mandal-level (subdistrict-level) attributes and secular and district-level time trends to account for and filter out the potential rise in households' awareness about program entitlements, the growing sophistication of audit teams, and the general rise in program activity.

Once we address these potential confounders, for our study period, we detect a positive but insignificant effect of social audits on employment generation and find no effect on the aggregate number of MGNREGA irregularities detected by the audit process. We find a marginally significant decline in the complaint amount per labor-related irregularity. This is accompanied by an increase in more sophisticated and harder-to-detect

5. Other likely effects and potential benefits from social audit participation are discussed later. 
material-related irregularities. ${ }^{6}$ These main results are robust to sensitivity checks that account for reporting biases and the potential endogeneity of audit intensity. We conclude that while audits may be effective in detecting irregularities, their impact, if any, on deterring malpractice is modest. This highlights the need for a time-bound process where transgressors are punished and responsibilities for follow up of social audit findings are laid out and credibly enforced.

The remainder of our paper is organized as follows: Section 2 presents a brief review of experiences with participation and bottom-up monitoring of public service delivery. We focus, selectively, on monitoring processes that quite closely resemble AP's social audits. Section 3 narrates the development of the social audit model of AP. Section 4 describes the data and presents descriptive statistics while Section 5 explains our conceptual framework. The estimation methodology is presented in Section 6. Results are discussed in Section 7 while Section 8 concludes and spells out the policy implications.

\section{Literature Review}

Our theoretical entry point is the question of whether a particular form of monitoring or auditing affects the quality of public service delivery. This is tangential to the broader theme of community-based development, and to questions of social accountability and whether "participation" works (e.g., Joshi and Houtzager 2012; Mansuri and Rao 2013). ${ }^{7}$ As noted by Aiyar et al. (2013: p. 251), the vision of the MKSS is embedded in a discourse on rights-based democratic action, where social audits not only represent an anti-corruption tool but "a platform on which citizens can be empowered to directly exercise their democratic rights." Social audits thus ensure bottomup involvement and opportunities for stakeholders to learn by doing through the repeated interaction with audit teams and as the process of MGNREGA delivery unfolds. ${ }^{8}$

6. In our conceptual framework, we link this to learning among beneficiaries, auditors, and transgressors and attempt to decipher the underlying logic of this shift.

7. Mansuri and Rao (2013) distinguish, conceptually, between "organic" and "induced" participation. The AP social audit model is an example of induced participation.

8. Conceptually this resembles Joshi and Houtzager's (2012: p.146) definition of social accountability as "citizen-led action for demanding accountability from providers" which privileges the "short" and direct route to service providers (Ringold et al. 2012). This is in contrast to the "long" and indirect route — via the electoral process - to improve service delivery (ibid.). 
In a particularly relevant study, Adato et al. (2005) seek to identify the impacts of "participation" on the quality of public work programs in South Africa. Evidence from 101 South African public work programs suggests that participation - conceptualized and measured as varying in degree, e.g., where the community is either the sole decision-maker, a joint decisionmaker or taking on an advisory role-is reported to strongly affect scheme performance as measured by the project budget share spent on labor, log number of days of work created, and the log number of training days on offer.

The suggestion, thus, is that local stakeholder involvement affects delivery along dimensions that the same stakeholders or beneficiaries can be expected to care deeply about. Even if such effects on the quality of delivery were not immediately discernible, for instance because learning operates with a time-lag, exposure to and participation in a social audit is likely to bolster awareness about MGNREGA entitlements and rules. ${ }^{9}$

Thus, a plausible conjecture is that participatory audits are more likely to be effective when addressing program outcomes with high beneficiary stakes. High stakes may not, however, be sufficient since beneficiaries also need the knowledge or capacity to act on their interests (as represented by their stakes). ${ }^{10}$ This begs the question of how best to strengthen beneficiary capacity. In MGNREGA, beneficiary learning appears to take place mainly "by doing" which may limit the effectiveness of participatory audits for outcomes that are less transparent and irregularities that are hard to detect. The capacity to detect is, in general, likely to depend on the complexity of relevant public program outcomes, as suggested by Khemani (2008). We return to this discussion later.

A few studies have touched upon the effectiveness of community-based monitoring. Bjorkman and Svensson (2009) (BS from now on) report the findings of experimentally induced community monitoring of health care provision in Uganda. Their intervention comprised of a two afternoon community meetings where a variety of participatory methods were introduced to "encourage community members to develop a shared view on how to improve service delivery and to monitor the provider" (ibid.). Information on patient rights and entitlements was disseminated while focus group discussions were organized to reach out to and absorb the views of marginalized groups. Local suggestions for improvements, and how to obtain these

9. Some such findings are reported in Aiyar et al. (2013) and, in addition to the above, include changes in the perceptions of government officials and greater confidence to approach such officials.

10. Ringold et al. (2012) highlight the importance of capacity. 
without injecting additional resources, were synthesized in an action plan. Simple as this may sound, it is not very different from what a well organized social audit would set out to achieve. ${ }^{11}$

The next step in the intervention closely resembles the public hearing in the AP social audit model: a one afternoon event at the health facility where all staff is present followed by a meeting between community members and health staff. The final and mandatory outcome of this process is a "contract," a shared and agreed plan of action that sets out what needs to be done, how, by whom, and by when.

The simplicity is an appealing aspect of the BS design and in spite of the limited duration, the reported impacts are remarkable. Apart from affecting process monitoring, service delivery improvements are reported for a series of relevant outcomes. There are ultimately impacts on health, including a radical decline in under-5 mortality.

In another community mobilization attempt, this time to improve the quality of public education provision in Uttar Pradesh (UP), Banerjee et al. (2010) shared information about the quality of schools, report cards showing children's reading ability and possible routes for improvement (e.g., via Village Education Committees) in community meetings where teachers, local government representatives, and village residents were all present. In contrast to BS, this particular evaluation found no impact of such village-wide meetings on community participation, teacher effort, or learning outcomes. ${ }^{12}$

If, as in the Uganda example, transformative effects can be achieved through such simple interventions, optimism on behalf of the AP social audit model seems justified given the many parallels between the BS intervention and the AP model. But what about the lessons from UP? A comparison between the UP and the Uganda interventions may, as Khemani (2008) suggests, throws up a fundamental contrast between the experience of or observability of substandard teaching and the quality of health services which local users may possibly have a better eye for and comprehension of. Put differently, community mobilization to improve education provision

11. There is a notable tension between the short-term and snapshot interventions BS (2009) and Banerjee et al. (2010) report on and the longer term engagements advocated and deemed necessary in the social accountability literature (Joshi and Houtzager 2012).

12. BS's and Banerjee et al.'s (2010) identification of impacts were made easier by randomized interventions: the attribution of desirable change to social audits, on the other hand, is made harder both by the absence of a credible source of exogenous variation in the quality of social audits and by the likelihood that problem areas are more likely to attract audits. 
may involve tougher pedagogical challenges. While stakes are expected to be high for both health and education, initial capacity constraints may be more binding for educational outcomes. A similar argument may apply to the distinction between labor and material-related irregularities in MGNREGA projects.

Another missing ingredient, both in the AP model and the UP intervention, is the "contractual outlay" to address grievances and how, by whom, and by what time these grievances should be addressed. This underscores the importance of effective grievance redressal in community-based monitoring efforts: hence, even if the AP social audit process is found to be effective in detecting irregularities, this would be a necessary but not sufficient condition to deter irregularities. What difference would it have made to BS's result if the final contract had been omitted? We return to this issue in our discussion of policy implications.

\section{The History of Public Works and the Genesis of the AP Social Audit Model}

Prior to MGNREGA, and like other Indian states, AP's performance in the implementation of public works was often dismal (Aiyar et al. 2013) and regularly undermined by the capture of vested interests, in particular through collusion between private contractors and local politicians (e.g., Deshingkhar and Johnson 2003). ${ }^{13}$

The social audit process was initiated in AP by setting up the Strategy and Performance Innovation Unit (SPIU) under the state's Rural Development Department in 2006. SPIU was mandated with conducting the social audits of MGNREGA projects and headed by a director, a state civil servant, and assisted by a consultant, formerly with the MKSS. Eventually, the responsibility for conducting regular and systematic audits of MGNREGA projects was transferred to a new and autonomous arm of the Department of Rural Development (the Society for Social Audits, Accountability and Transparency (SSAAT)) in May 2009. As of today, the SSAAT director is an independent consultant and not part of the state government.

This initiative makes AP unique and distinct from other Indian states where audits have either not been conducted or been implemented in an

13. As part of our retrospective household survey in 2011, we asked 1,500 beneficiary households in AP about their satisfaction with the scheme. While indicative, we found a strong stakeholder endorsement and satisfaction with MGNREGA in AP. 
ad hoc and unsystematic manner. ${ }^{14}$ AP's record on social audit implementation is similarly unique. Systematic and standardized audits have been carried out in all 23 districts of AP with an average of over two rounds of audits completed per GP between 2006 and 2010.

\subsection{The Social Audit Process in AP $P^{15}$}

The first step in conducting the social audit is a notification to the relevant sub-district or mandal office with reference to Right to Information (RTI) obligations and requesting unrestricted access to muster-rolls and other relevant MGNREGA project documents (ibid.). A team comprising state and district auditors will, upon their arrival in the mandal headquarter, first recruit and then, in a two-day workshop, intensively train village social auditors about MGNREGA rights and regulations, how to conduct the social audits, and how to obtain information under RTI legislation (ibid.). The village social auditors are MGNREGA beneficiaries and residents of the mandal.

The social audit teams will then, over a period of about a week, organize social audits in all GPs of the mandal. In each GP, official labor expenses are verified by visiting laborers listed in the worksite logs ("muster-rolls"). Complaints by individuals or groups of beneficiaries and the audit team are recorded and attested using a standardized audit report template. ${ }^{16}$ For verification of material expenditure, the audit team is mandated to undertake worksite inspections. Except for the more obvious and easy-to-detect (ETD) irregularities such as "ghost" or non-existent projects, the verification of material expenditure is typically perceived to be more complex and demanding. Thus, the social audit process in AP uniquely combines a top-down approach (i.e., timing and conduct of audits controlled by the SSAAT) with grassroots participation (i.e., village social auditors and local stakeholders).

Once the audits of all GPs have been completed, a mandal-level public hearing with mandatory attendance for all implementing officials is organized to discuss the audit findings. Those present, typically include "wage seekers from the villages in the mandal, the social audit team, branch postmaster, key implementing officials, members of the vigilance cell, elected representatives, and a district-level ombudsman" (Aiyar et al. 2013: p. 261).

14. Even though some states have recently responded to the Act by conducting "regular" social audits, the exercise has been largely superficial with claims of no irregularities in program implementation.

15. In narrating the content of the AP social audit model, we draw extensively on Aiyar et al. (2013).

16. The auditors are expected to verify labor records for all beneficiaries. This may not be true in practice. 
Complaints will be read out, testimonies verified, and accused officials given an opportunity to defend themselves.

After the public hearing a decision taken report (DTR) is created by the officer presiding over the hearing. In this report the responsibility for each confirmed malfeasance is pinned on a program functionary or, as the case may be, on multiple functionaries. ${ }^{17}$ Until 2010, the mechanism for redressing issues raised by the social audit and mentioned in DTRs was weak. ${ }^{18}$ However, in 2010, the state set up a vigilance cell within the Department of Rural Development (Aiyar et al. 2013). Under this mechanism, copies of the DTRs are sent to key program functionaries for follow-up action within days of the public hearing, including the district vigilance officer. The vigilance office then issues an action taken report (ATR) which lists the action taken against errant officials in the DTR (ibid.).

\section{Data}

Our panel data were extracted and codified from the official and original Telugu social audit reports for 100 randomly sampled mandals across eight districts of AP. ${ }^{19}$ In each randomly chosen mandal, three GPs were selected based on the following criteria: the GP which was the administrative headquarter of the mandal, one GP randomly selected from all GPs reserved for a female sarpanch, and one randomly selected from GPs not reserved for a female sarpanch in that mandal in 2006. Our initial sample, thus, comprises 300 GPs from 100 mandals.

The GP-audit reports have two components: a standard audit report card which records the date of the audit along with the demographic characteristics of the GP, and more importantly, audit team impressions about process performance since the last audit including a financial misappropriations estimate. These impressions and estimates are based largely on the second component of the audit report - the list of complaints filed by individuals, groups, or by audit team members. The complaints are recorded during the

17. The SSAAT has introduced checks and balances to prevent local program functionaries who are being audited from corrupting audit team members.

18. In the above parlance, the social audit process lacked procedural tightness.

19. These eight districts were Mahbubnagar, Medak, Nizamabad, Warangal, and Khammam (north or the Telangana region), Anantpur and Kurnool (south or the Rayalseema region), and Guntur (west or the coastal region). MGNREGA was implemented in February 2006 in all these districts, except Kurnool and Guntur, which implemented the program from April, 2007 onward. 
door-to-door verification of labor expenditures and during project site inspections to verify material expenditures by technical members of the audit team. Each complaint is supported by affidavits and brought up during the public hearing. As noted earlier, during the public hearing the responsibility for each complaint is pinned on one or multiple MGNREGA functionary(-ies). We use data on all verified complaints, following the public hearing.

These data are available from the first round of audits that began in 2006 and until 2010. ${ }^{20} \mathrm{We}$ construct a panel of audit reports for each GP with an average of over two reports per GP for the period 2006-10. We supplement the official audit data with data from interviews with the mandal parishad development officer (MPDO) and the GP sarpanch elected in 2006 for a five year term. These retrospective surveys were conducted during April-June, 2011. Data from the Census (2001) provide village-level characteristics such as infrastructure and access to public services.

In addition to the audit data, we also obtained information on program performance from the Department of Rural Development's (AP) web site for the financial years 2006-07 to 2010-11. ${ }^{21}$ These data on program expenditures and employment were cumulated across financial years prior to the financial year in which the audit occurred and then linked to each GP by the audit date. The data, therefore, inform us about program expenditures and person days of work covered in each audit. We also linked program expenditures and person days of work generated post audit (and before the next audit) to each GP to assess the effect of an audit on subsequent program performance.

\subsection{Descriptive Statistics}

The social audit data facilitate comparisons by audit round and complaint type. Table 1 presents a breakdown of the average number of complaints by type across all rounds. We categorize complaints into three typeslabor related, those related to materials used in MGNREGA projects, and the provision of work-site facilities mandated by the Act-labeled "other complaints". Labor complaints account for $87 \%$ of all complaints. This is not surprising since the problems that trigger labor complaints more directly affect beneficiary households. At the same time, the average real amount per

20. Original audit reports that were missing were supplemented with abridged versions of the audit reports available from the SSAAT web site: http://125.17.121.162/SocialAudit/ Web site

21. The following link was accessed between July-August, 2013 to obtain information on program expenditures and employment: http://nrega.ap.gov.in/Nregs/FrontServlet?requestT ype=NewReportsRH\&actionVal=Display\&page=Newreportcenter_ajax_eng 
T A B LE 1. Summary Statistics Across All gram panchayats

\begin{tabular}{lccccc}
\hline Variable & Number of audits & Mean & Std. dev. & Min. & Max. \\
\hline All complaints & 711 & 5.822 & 5.298 & 0 & 43 \\
Labor complaints & 711 & 5.061 & 4.594 & 0 & 30 \\
Material complaints & 711 & 0.683 & 1.519 & 0 & 18 \\
Other complaints & 711 & 0.077 & 0.306 & 0 & 3 \\
\hline
\end{tabular}

Source: Authors' calculations from data extracted from official social audit reports.

material-related irregularity (₹28,786) was more than twice the real amount per labor-related irregularity (₹10,289) over the three audit rounds.

Table 2 shows trends by complaint type. If we restrict attention to audit rounds $1-3$, there is a discernible rise in the total number of complaints between rounds 1 and 3 (Row 1), driven mainly by a disproportionate increase in the number of material complaints $(173 \%)$ relative to the increase in the number of labor complaints $(13 \%) .^{22}$

T A B LE 2. Number of Complaints by Audit Round

\begin{tabular}{lccc}
\hline & Audit 1 & Audit 2 & Audit 3 \\
Variable & $N=284$ & $N=261$ & $N=166$ \\
\hline All complaints & 5.123 & 6.249 & 6.349 \\
& $(4.306)$ & $(5.375)$ & $(6.487)$ \\
Labor complaints & 4.602 & 5.475 & 5.199 \\
& $(4.067)$ & $(4.995)$ & $(4.739)$ \\
Material complaints & 0.415 & 0.689 & 1.132 \\
& $(0.740)$ & $(1.186)$ & $(2.541)$ \\
Other complaints & 0.105 & 0.084 & 0.018 \\
& $(0.370)$ & $(0.304)$ & $(0.133)$ \\
\hline
\end{tabular}

Source: Authors' calculations from data extracted from official social audit reports.

Note: Standard errors in parentheses.

Table 3 disaggregates the type of complaint by audit round and captures broad trends: the rise in labor complaints appears to be mainly driven by administrative inefficiencies, specifically, a sharp rise in complaints for

22. There are notable differences in trends in irregularities across districts as shown in Table A1 in the Appendix. The district-wise trends in the number of complaints suggest that the five Telangana districts feature among the seven worst districts, with Anantapur and Kurnool only marginally worse than the best Telangana district (Medak). For material complaints, the Telangana districts are the five worst districts. This is suggestive of a different political economy of MGNREGA irregularities in Telangana. It is also evident that the average number of complaints is increasing, and dramatically in four of the five Telangana districts, with Khammam as the only and very notable exception. For Anantapur and Kurnool, audit 3 numbers are lower than everywhere else, but we have few third round audits in these districts. 
T A B LE 3 . Proportion of Type of Complaint by Audit Round

\begin{tabular}{lccc}
\hline Variable & Audit 1 & Audit 2 & Audit 3 \\
Labor related & $N=262$ & $N=236$ & $N=151$ \\
\hline Non-payment/delay in wages & 28.385 & 34.778 & 47.802 \\
& $(29.469)$ & $(32.982)$ & $(33.870)$ \\
Non-provision of work & 15.012 & 10.001 & 7.697 \\
& $(23.794)$ & $(20.238)$ & $(18.048)$ \\
Impersonations/benami wage payments & 19.301 & 26.023 & 16.901 \\
& $(27.418)$ & $(30.511)$ & $(25.996)$ \\
Excess wage payments/bribes & 19.883 & 15.850 & 14.376 \\
& $(26.958)$ & $(23.399)$ & $(20.559)$ \\
Wage records missing & 6.6034 & 6.023 & 6.711 \\
& $(14.371)$ & $(14.807)$ & $(15.634)$ \\
\hline Material related & $N=86$ & $N=96$ & $N=65$ \\
\hline Non-existent work & 14.438 & 28.675 & 25.146 \\
& $(32.070)$ & $(39.484)$ & $(37.783)$ \\
Poor quality of materials & 44.864 & 18.663 & 6.239 \\
& $(47.489)$ & $(34.787)$ & $(24.206)$ \\
Excess payments/bribes & 15.310 & 30.092 & 50.727 \\
Expenditure records missing & $(35.073)$ & $(40.253)$ & $(43.325)$ \\
& 4.360 & 4.513 & 8.183 \\
& $(19.247)$ & $(18.961)$ & $(23.125)$ \\
\hline
\end{tabular}

Source: Authors' calculations from data extracted from official social audit reports.

Note: Standard errors in parentheses. Statistics conditional on a labor/material complaint being filed in an audit in a GP. Missing category of "other" in both labor and material-related complaint.

delayed payment or non-payment of wages over the three audit rounds. In contrast, we register a steep decline in complaints related to non-provision of work. Impersonations/benami wage payments and excess wage payments/ bribes also decline, but marginally, between audits 1 and 3 . There is no significant change in the audit teams' access to wage records as shown in the row "wage records missing." For the material component, grievances related to "non-existent work" and "excess payments/bribes" rose significantly alongside a sharp drop in irregularities related to "poor quality of materials." We also observe an increase in missing materials expenditure records. ${ }^{23}$

Finally, Table 4 summarizes program outcomes audited in each round. Real program expenditures more than doubled in the period after the first audit. Water conservation projects had the highest share of total program expenditure in audit 1 but this share along with that of drought and flood control fell in subsequent audits. There was a marginal increase in the share

23. Note that if expenditure records (viz. receipts of materials purchased) are not available to the audit team and those expenditures have been officially incurred, the auditors interpret this as leakage of program funds. 
T A B LE 4. Program Performance by Audit Round

\begin{tabular}{lccc}
\hline & Audit 1 & Audit 2 & Audit 3 \\
& $N=282$ & $N=255$ & $N=161$ \\
\hline Variable & 8.906 & 22.488 & 23.117 \\
& $(14.1)$ & $(22.944)$ & $(24.725)$ \\
Protal expenditure (in 2006 rupees, lakhs) & 0.441 & 0.287 & 0.190 \\
& $(0.305)$ & $(0.243)$ & $(0.189)$ \\
Proportion of drought and flood control & 0.086 & 0.027 & 0.012 \\
& $(0.160)$ & $(0.081)$ & $(0.072)$ \\
Proportion of rural connectivity works & 0.023 & 0.086 & 0.089 \\
& $(0.081)$ & $(0.153)$ & $(0.138)$ \\
Total employment generated in person days & 11615.71 & 31314.55 & 33104.46 \\
& $(18626.6)$ & $(36375.54)$ & $(36721.22)$ \\
Proportion of SC person days generated & 0.298 & 0.275 & 0.253 \\
& $(0.264)$ & $(0.221)$ & $(0.179)$ \\
Proportion of ST person days generated & 0.122 & 0.136 & 0.156 \\
& $(0.249)$ & $(0.268)$ & $(0.276)$ \\
\hline
\end{tabular}

Source: Authors' calculations from data extracted from official social audit reports.

Note: Standard errors in parentheses. Expenditure deflated using the consumer price index for rural labor (http://labourbureau.nic.in/indtab.pdf), with base year as 2006. Rows (2)-(4) are calculated as proportions of row (1). Rows (6)-(7) are calculated as a proportion of row (5).

of program expenditures on rural connectivity works from audit 1 to 3 . On employment generation, total person days increased almost threefold during this period but there were no significant changes in the share of SC (marginal decline) or ST (marginal increase) person days. Thus, overall, we observe a sharp rise in program activity during the study period.

While the summary statistics are suggestive of the trends in program performance, our main challenge is to obtain convincing clues about the impacts of social audits on corruption and on the quality of program delivery. We introduce our conceptual framework before addressing the methodological challenges.

\section{Conceptual Framework: Linking Stakes, Capacity, and Learning}

Except for Joshi and Houtzager's (2012: p. 155) emphasis on the need "to examine social accountability actions as one part of a broader and longer process of engagement between collective actors and the state", the existing literature tends to bypass the repeated behavioral interactions between and learning by beneficiaries, social audit teams, and public officials (transgressors) that repeated social audits may give rise to. 
This section outlines some basic assumptions we make about the behavioral response of all actors in the audit process that aid the interpretation of our empirical results. We first assume that the state commits to conducting regular social audits. However, the first round of the social audit, given low state credibility, takes public officials (or transgressors) by surprise. Further, the cost of effort for basic program delivery transgressions is low. Second, local MGNREGA beneficiaries have high stakes in employment availability and in timely and due pay. There is, moreover, sufficient capacity on the part of audit teams and local beneficiaries to detect transgressions in basic program delivery.

As a result, we expect more ETD irregularities in the initial audit round. In subsequent audit rounds, beneficiaries may become more effective participants while auditors become more adept. We should, thus, observe a decline in ETD irregularities. At the same time, transgressors expect audits in the future and benefit from staying one step ahead of the auditors.

We thus anticipate an evolving dynamic process with improved auditing and signs of more effective local participation through learning. The drawback is that transgressions may also become more sophisticated. The introduction of monitoring may thus result in substitutions of one type of irregularity for another as transgressors learn to manipulate the new system while discovering other avenues for rent extraction (Olken and Pande 2011). Hence, if we assume that auditors' learning is unable to catch up with learning by those who are audited, then we would observe more harder-to-detect irregularities. ${ }^{24}$ Figure 1 links, in a simplified manner, our discussion of beneficiary capacity and stakes to this evolving process of learning and response.

Our assumptions are borne out by the data. While AP had conducted multiple audits in all mandals by 2010-11, state commitment to monitoring had no precedent. Further, in the first audit round, $80 \%$ of all labor-related complaints were filed by local beneficiaries. Roughly half of these were in the "hard-to-detect (HTD)" category. Among beneficiaries, therefore, stakes appear to trump complexity from the start. In contrast, social audit teams submitted $80 \%$ of the material complaints in the first audit round. By audit round 2 , there was already a greater diversity in beneficiary complaints, with a higher share of material complaints, spread across ETD and HTD.

24. However, even if audits become more effective in detecting irregularities, deterrence may remain weak. In order to change transgressor behavior, we thus need to assume either that being caught is sufficiently "costly" even in the absence of formal punishment or that beliefs about strong, future punishment are widespread. 
F I G U E 1. Beneficiary Stakes and Capacity of Participatory Social Audits

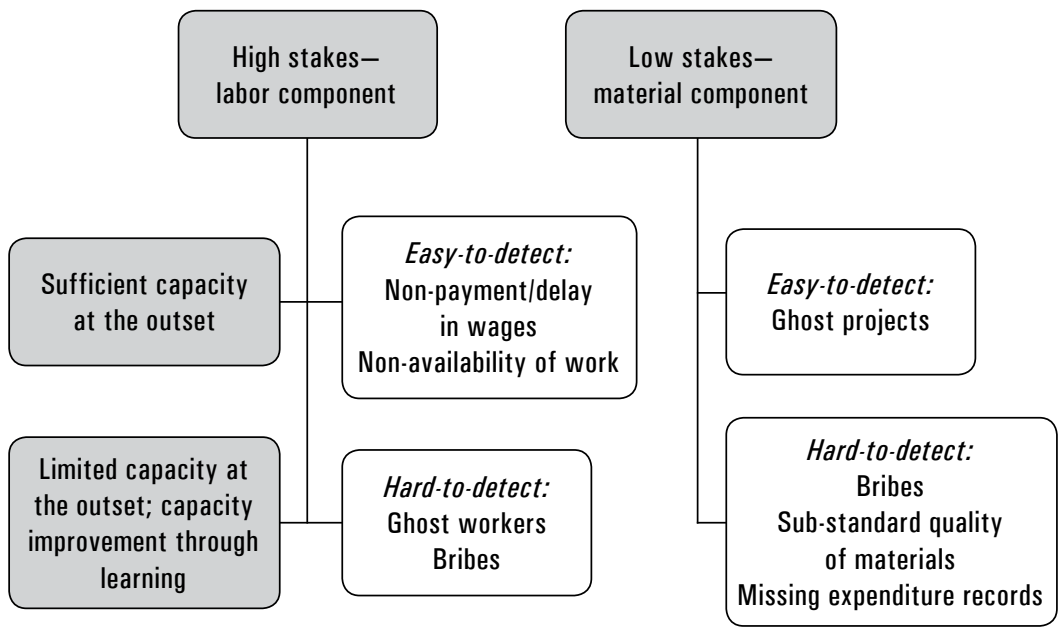

Source: Authors' calculations from data extracted from official social audit reports.

Note: ETD labor-related irregularities comprise of non- and delayed wage payment and non-availability of work. HTD labor-related irregularities comprise of benami and bribes. ETD material-related irregularities relates to "ghost" or non-existent project. HTD material-related irregularities comprise material bribes, substandard material quality, and missing material records.

By audit round 3, the latter accounted for $60 \%$ of the material complaints filed by beneficiaries.

Contrast this with the complaints filed by the social audit team which divide, more sharply, between ETD and HTD irregularities, for labor and materials and change little over time: the share of HTD irregularities in all labor complaints submitted by the audit team is never below $88 \%$. For material complaints, the corresponding audit team figure is $76 \%$. The share of HTD irregularities filed by the audit team for both labor and material complaints, however, increases by about 10 percentage points from audit round 1 to 3 . These observations suggest that the social audit process imparts substantive learning on local beneficiaries. At the same time, and given that the large majority of social audit team complaints involve HTD irregularities, beneficiary learning is not sufficient to ensure that the participatory part of the process can fully handle the more complex labor and material irregularities. The top-down part-represented by the social audit team-and the participatory process, thus, appear to perform vital complementary roles. ${ }^{25}$

25. Olken (2009) finds that top-down audits may be more effective in curtailing corruption in public programs as opposed to a bottoms-up approach envisaged by community monitoring. 
To summarize, if audits effectively detect malfeasance and the threat of punishment for malfeasance is credible, we expect ETD irregularities to decline with repeated audits. At the same time, we expect more HTD irregularities in later audit rounds due to the increasing sophistication of transgressors even as auditors and beneficiaries learn. ${ }^{26}$

\section{Methodology}

As noted, we take advantage of the panel structure of the data to assess whether program implementation improves with repeated social audits within the same mandal, over time, while controlling other trends that could potentially impact corruption and the quality of program delivery.

Our main specification is given by:

$$
\begin{aligned}
\text { Outcome }_{n j k l t}= & a_{0}+\sum a_{n} \text { Audit }_{n+} a_{4} \mathbf{X}_{j k l}+a_{5} D_{k}+\sum \eta_{t} \text { Year }_{t} \\
& +\sum \gamma_{l t}\left(D_{l} * \text { Year }_{t}\right)+\mu_{n j k l t}
\end{aligned}
$$

The analysis is conducted at the GP-audit level. The findings of social audit $n$ in GP $j$ in mandal $k$ in district $l$ in year $t$ is denoted by Outcome $e_{j k l t}$. Our outcomes comprise the different complaint variables described in section 4 . The main coefficient of interest is the round of the social audit, or Audit ${ }_{n}$, $n$ taking values 2 and 3 with the first audit as the reference year. The coefficient on $\mathrm{Audit}_{n}$ will tell us whether, relative to the first audit, irregularities in program implementation are higher or lower. $\mathrm{X}_{j k l}$ is a vector of timeinvariant GP-level characteristics that includes attributes of the sarpanch elected in 2006 (for a five year term) such as gender, caste, education and age, the GP's access to health and education facilities, and the distance from the nearest town. It also includes a dummy variable for whether the GP is the mandal headquarter.

A few factors may confound the interpretation of $a_{n}$. First, recall that the audit is conducted at the level of the mandal. All GPs within a mandal are audited by a single audit team within a period of about one week. Some

Villagers' perception of corruption in a village road construction program in Indonesia rose by only $0.8 \%$ when actual corruption in the program rose by $10 \%$.

26. In an ideal scenario, one would use independent measures of corruption or malfeasance in the program. Unfortunately, data are available only for malfeasance reported in the social audits. This is likely to be an underestimate of the true level of corruption or the true number of irregularities since some beneficiaries may not register their complaints, e.g., due to threats or intimidation. 
mandals may be systematically better or worse at administering the program since the mandal-level bureaucracy plays a critical role in MGNREGA implementation. We therefore use mandal-level dummies, $D_{k}$, to control this unobserved variation in the timing of the audit and in mandal-level implementation capability.

Second, the social audit findings, reported as the complaint types discussed earlier, might be influenced by (a) changes in awareness about program entitlements or beneficiary confidence in the integrity of the audit process because of repeated exposure and (b) by improvements in audit quality as audit team members become more adept at detecting discrepancies. For the former, with constant implementation quality, we would observe an increase in the number of beneficiary complaints over time.

To capture (a) we account for linear time trends by including dummies $\left(\right.$ Year $_{t}$ ) for the year in which the particular audit was conducted (dummy for each year between 2006 and 2010). The assumption here is that average awareness among beneficiaries would be higher in say, 2008 relative to 2006, due to repeated program exposure and irrespective of the number of audits conducted. A similar argument holds for (b).

Third, as pointed out earlier, some districts are more likely to be more (less) effective MGNREGA implementers. For instance, biometric beneficiary identification was introduced in some districts before others. Such district-level variations in technological advances, in program activity (i.e., number of MGNREGA projects or program expenditures) or in bureaucratic capacity, could influence the quality of program delivery and reported irregularities directly. Thus, to account for differences in program implementation trends across districts, we interact the dummy variable for each district with the dummy for each audit year $\left(D_{l} *\right.$ Year $\left._{t}\right)$ and include these as additional controls.

In our second line of inquiry, we study the effect of audits on real program expenditures and employment generation. Specifically, we estimate the following model:

$$
\begin{aligned}
\operatorname{NREGA}_{j k l,(t+1)}= & \beta_{0}+\sum \beta_{n} \text { Audit }_{n, t+} \beta_{3} \boldsymbol{X}_{j k l}+\beta_{4} D_{k} \\
& +\sum \theta_{t} \text { Year }_{t}+\sum \delta_{l t}\left(D_{l} * \text { Year }_{t}\right)+\varepsilon_{n j k l t}
\end{aligned}
$$

$N R E G A_{j k l,(t+1)}$ is employment and expenditure under the program in GP $j$ in mandal $k$ in district $l$ at time $t+1$. Audit ${ }_{n, t}$ is a dummy variable for the $n$th audit in period $t$. The other variables are as described for our first specification. Note that our data pertain to audits 1 to 3 . Since the outcome variable relates to the years between successive audits, the audit dummy variables 
included in the specification are for audits 1 and 2 for the years in our study. The corresponding MGNREGA data are for the cumulated outcome after the $n$th audit and before the $(n+1)$ audit. Thus $\beta_{n}$ is an indicator of the impact of an audit on subsequent expenditures and employment generated under the program.

A remaining challenge is to decipher the interpretational possibilities that social audit data, in their present form, give rise to. Put differently, even if the social audits were implemented as RCTs with "impacts" amenable to robust identification, beneficiary complaints data could suffer from reporting biases that our (or an RCT-based) methodology is unable to fully account for. For instance, a decline in complaints may be due to intimidation by transgressors of beneficiaries who complained in previous audit rounds. Thus, fewer program irregularities may not reflect a genuine decline in malfeasance. In a similar manner, local politics may affect complainant behavior with a rise in complaints reflecting political maneuvering to harm, e.g., an incumbent.

To address this concern we undertake a robustness check of our main results by restricting the analysis to complaints filed by the audit team alone. We thus assume that the members of the audit team are unlikely to be intimidated or threatened and less likely to be swayed by local political biases.

\section{Results}

We first discuss results for the number of reported irregularities followed by program performance outcomes. Table 5 presents results on variation in the reported total, labor-related and material-related irregularities across audits, controlling for elected sarpanch and GP attributes, overall time trends (which, as noted, pick up changes in audit quality and awareness levels), district-specific trends, and mandal fixed effects. The specification, thus, assumes that unobservable differences in mandal characteristics and district specific trends may influence program quality. In column 1, the dependent variable is the total number of complaints filed in a social audit, while in columns 2 and 3 the outcomes of interest are the total numbers of labor and material complaints, respectively. ${ }^{27}$

27. When we account for whether the district belongs to the most disadvantaged and politically sensitive area of Telangana (north-west AP) or not, the results suggest that while the total number of complaints decreased by audit 3 in non-Telangana districts, Telangana experienced increases in complaints in both audits 2 and 3. Non-Telangana districts showed a decline in labor complaints filed in audit 3 relative to audit 1. Material-related complaints 
T A B L E 5 . Effect of Social Audits on Total Irregularities

\begin{tabular}{lccc}
\hline & All irregularities & $\begin{array}{c}\text { Labor-related } \\
\text { irregularities }\end{array}$ & $\begin{array}{c}\text { Material-related } \\
\text { irregularities }\end{array}$ \\
& $(1)$ & $(2)$ & $(3)$ \\
\hline (1) Audit 2 & $2.528^{*}$ & 1.740 & $0.818^{* *}$ \\
(2) Audit 3 & $(1.430)$ & $(1.158)$ & $(0.407)$ \\
& 2.695 & 1.409 & $1.345^{* *}$ \\
(3) Constant & $(1.973)$ & $(1.680)$ & $(0.553)$ \\
& 9.457 & $11.73^{* *}$ & -2.788 \\
(4) Audit 3 - Audit 2 & $(6.375)$ & $(5.565)$ & $(1.694)$ \\
& 0.166 & -0.330 & $0.526^{*}$ \\
R-square & $(1.028)$ & $(0.963)$ & $(0.275)$ \\
Number of audits & 0.420 & 0.448 & 0.282 \\
Year fixed effects & 685 & 685 & 685 \\
Mandal fixed effects & $\mathrm{Y}$ & $\mathrm{Y}$ & $\mathrm{Y}$ \\
District-specific trends & $\mathrm{Y}$ & $\mathrm{Y}$ & $\mathrm{Y}$ \\
\hline
\end{tabular}

Source: Authors' calculations from data extracted from official social audit reports.

Notes: All specifications include controls for sarpanch's age, sex, caste, education, prior political experience; availability of bank, communication, medical facility, and middle school in the GP; proportion of cultivated area which is irrigated, distance to town, population density, and whether the GP is the mandal headquarter. Standard errors clustered at the GP level reported in parentheses. ${ }^{*}{ }^{*}$ significant at $1 \%,{ }^{*} 5 \%$, and ${ }^{*} 10 \%$.

In column 1 , the coefficient on audit 2 is positive and significant while the audit 3 coefficient is insignificant. Thus, overall, aggregate irregularities were higher in audit 2 than in audit 1 while there is no significant difference between audits 2 and 3 (row 4). Next, column 2 shows that labor complaints were not higher in rounds 2 and 3 relative to round 1 . However, in column 3 we find more material complaints in audit rounds 2 and 3: a $197 \%$ and $324 \%$ increase, respectively, relative to round 1 . There were also more such complaints in audit 3 than in audit 2 (row 4). Thus, there appears to have been a secular rise in irregularities related to material expenditure. Hence the increase in total complaints, albeit insignificant in audit 3, was likely driven by the rise in material complaints.

In Table 6, we classify labor- and material-related irregularities into "ETD" and "HTD" as discussed in the conceptual framework section earlier. Hence, within the labor component of the program - non-payment or delays in wage payments and non-provision of work are ETD while benami and bribe-related irregularities are classified as HTD. The results suggest that any increase in the number of labor-related irregularities was due to more

were significantly higher in Telangana districts in audit 3. It is possible that the effect of social audits in non-Telangana regions is insignificant because the levels of corruption or program mismanagement are very low in those areas, to begin with. 


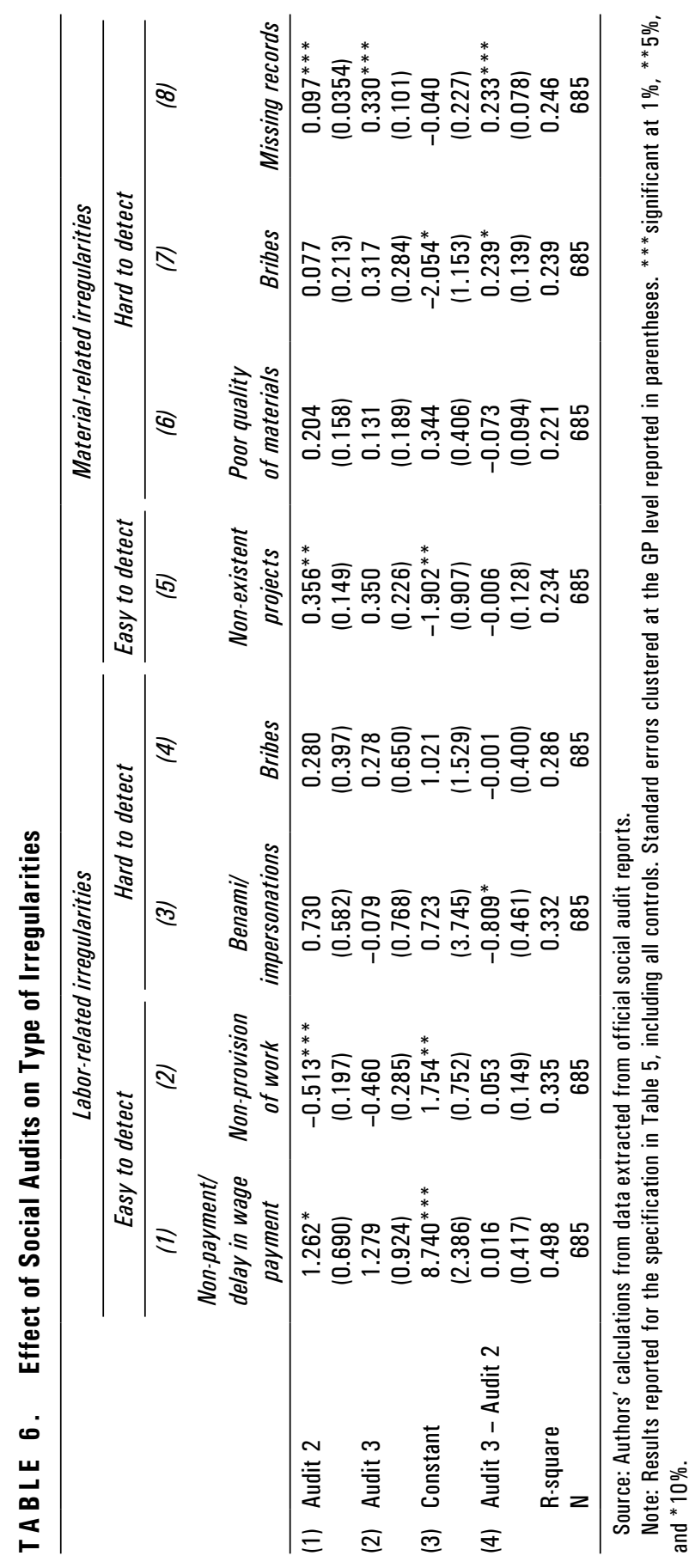


complaints about non-payment or delay in wage payments in audit 2 relative to audit 1 (column 1). These were, however, not significantly higher in audit 3 relative to audit 1 or between audits 2 and 3 (column 1, row 4 ). We thus conclude that there was an insignificant increase in the number of complaints related to non-payment or delay in wage payments over the three audit rounds. Interestingly, the number of complaints related to non-provision of MGNREGA work declined in both rounds 2 and 3, albeit insignificantly in the latter as shown in column 2 . As a result, there was no significant decline in irregularities related to the non-provision of work over successive audits (column 2, row 4). Further, there was an insignificant effect of audits 2 and 3 on irregularities due to corrupt practices (i.e., benami wages, bribes, etc. in columns 3 and 4) relative to round 1. However, the negative coefficient in row 4, column 3, suggests that irregularities related to ghost workers may have declined between audits 2 and 3 .

Columns 5-8 show that the increase in material-related complaints in audit 2 was driven by the rise in ETD ghost or non-existent projects (column 5, row 1), and the harder-to-detect irregularities due to missing official records on material expenditure (column 8, row 1). However, by audit 3 , the number of non-existent projects was not higher than in audit 1 (column 5 , row 2). Overall, the secular increase in material-related complaints over the three audit rounds seems to have been driven by the significant increase in bribes and missing expenditure records (columns 7 and 8, row 4).

In Table 7, we present results for the effect of audits on direct measures of program performance, as in equation (2). Our sample is restricted to GPs with three audits between 2006 and 2010. Relative to program performance post audit 1 , there was an insignificant increase in real program expenditures post audit 2 as shown by the coefficient on audit 2 in column 1 . Interestingly, there was a marginal decline in the proportion of program expenditures on rural roads projects where the avenues for corruption may be higher as shown in column 2 (World Bank 2011). Total MGNREGA employment generated increased insignificantly (column 3) while there was no change in the proportion of SC and ST person days in total MGNREGA employment (columns 4 and 5). These findings line up with those in Tables 5 and 6 - suggesting that the impacts of audits on program outcomes were, at best, marginal.

To summarize, we observe insignificant changes in the ETD complaints, but a substantive rise in HTD, material complaints. These patterns are consistent with the earlier discussion of stakes and evidence on beneficiary learning. In spite of such learning and the greater capacity of the participatory part of the audit process to detect irregularities, illustrated by the 
T A B L E 7. Effect of Social Audits on Program Performance

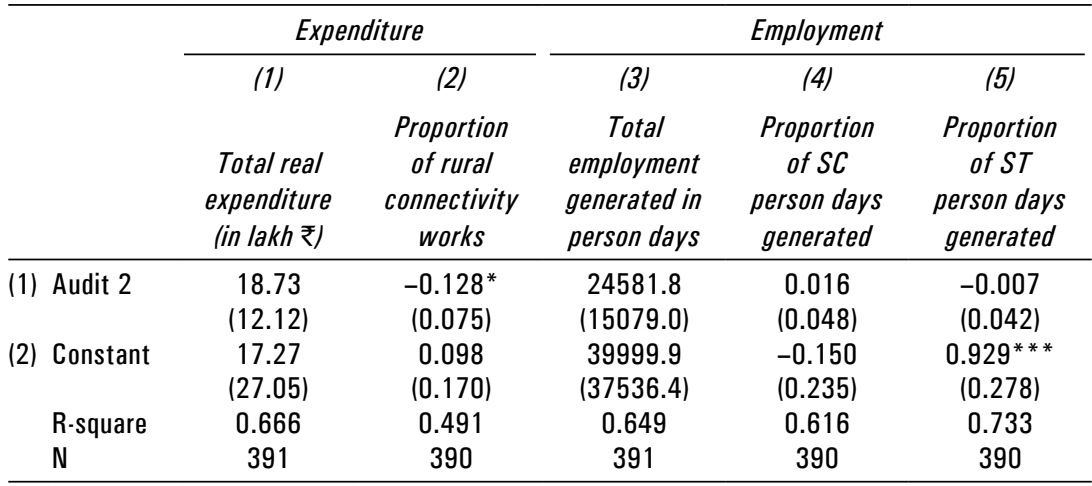

Source: Authors' calculations from data extracted from official social audit reports.

Notes: Results reported for equation 2 in the text. Controls as described in Table 5. Columns (2) and (4)-(5) are calculated as proportions of columns (1) and (3), respectively. Standard errors clustered at the GP level reported in parentheses. ${ }^{* *}$ significant at $1 \%$, ${ }^{*} 5 \%$, and ${ }^{*} 10 \%$.

increasingly advanced complaints submitted by beneficiaries, the social audits were ineffective in systematically reducing the ETD irregularities. We interpret the observed rise in material-related malfeasance, without an accompanying reduction in the ETD irregularities, as an underlying change in the anatomy of corruption and a failure of the social audit process to deter malpractice: it appears that transgressors adapted to the new monitoring regime by looking for additional avenues of rent extraction as suggested by Olken and Pande (2011). ${ }^{28}$ Given that the average real amount per materialrelated irregularity was significantly greater than for irregularities related to labor (mentioned earlier), the structural shift in program leakages suggests that the benefits from rent extraction were sufficiently higher than the cost of effort and any expected punishment following detection of materialrelated theft.

28. Quoting Aiyar et al. (2013):

With the help of an information technology company-Tata Consultancy Servicesthe government of Andhra Pradesh developed an end-to-end management information system (MIS) through which job cards, work estimates, and payment orders are issued. The data are collected and input (entered electronically) at the mandal level, and consolidated at the state level. Information on each job card holder, including number of days worked and total wages received, is accessible through the MIS. All data are public and available for scrutiny. To streamline payment processes, wages are paid directly through workers' post office or bank accounts. (Authors' emphasis) 


\subsection{Robustness Checks}

The results on leakages, so far, are from a sample with variation in the number of audits across mandals. It is possible that mandals which were audited more frequently during 2006-10 report higher incidence of MGNREGA irregularities because they were relatively more corrupt. As a result, the coefficient on audit 3 would, for instance, be biased upwards. To account for this possibility, we report the results in Table 8 for the data restricted to GPs where three audits were conducted during 2006-10. Our results are largely unchanged from those for the unrestricted sample. While the number of irregularities related to non-payment and delays in wage payment (column 1, rows 1 and 2) and bribes (column 4, row 1) increased, complaints related to non-provision of MGNREGA work (column 4, row 1) declined relative to audit 1 . The secular rise in material complaints was driven by an increase in material-related bribes (column 7 , row 4 ) and missing expenditure records (column 8, row 4).

So far, we have analyzed the data for complaints filed by individuals, groups of beneficiaries as well as discrepancies unearthed by the audit team itself. Even though our specification attempts to address the challenges posed by beneficiary learning, other beneficiary biases and threats to or intimidation of beneficiaries, may influence the reporting of irregularities. This in turn would influence our interpretation of outcomes of interest and get reflected in changes in the number of irregularities over time. To address this possibility, we restrict attention to the irregularities registered by the audit team which should be immune from such biases. As before, improvement in audit quality is accounted for by the time trends. Table 9 shows these results for the same outcomes reported earlier. Crucially, our conclusions are unchanged when we observe the coefficients reported in row 4 across all columns. In Table 10, we include an additional control for the real expenditures under the program in each GP in the financial year(s) prior to the date of the audit (or for the period audited) to account for the possibility that the number of irregularities would rise if the intensity of the program increases (even after controlling secular trends). Once more, our results are consistent with those in previous tables.

A final interpretational concern is from a welfare perspective: it may be more relevant to study whether the rupee value (in real terms) per complaint has changed with more audits rather than the number of complaints. Hence, while the number of complaints has risen, the rupee amount of these irregularities may have declined when compared to the early days of the program. Table 11 shows the results for the same specifications as earlier but with 


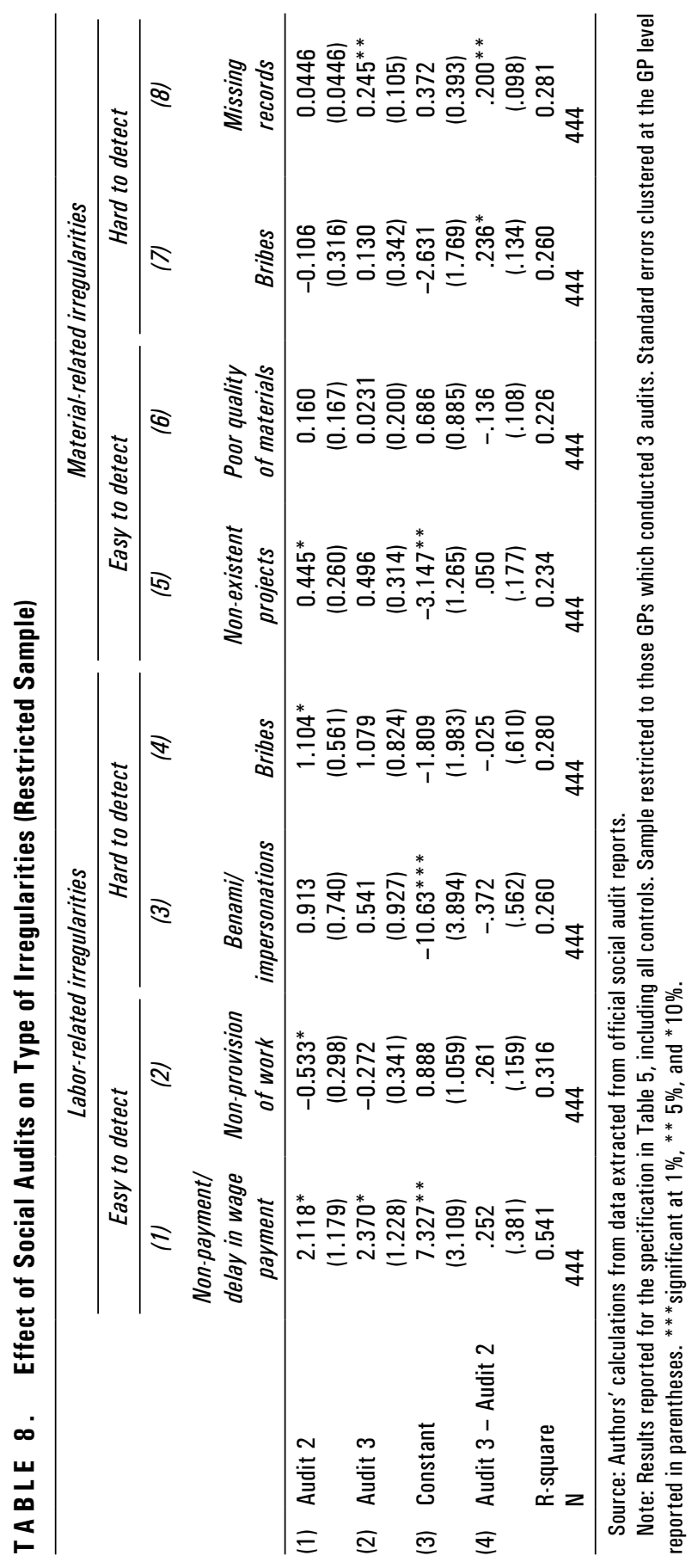




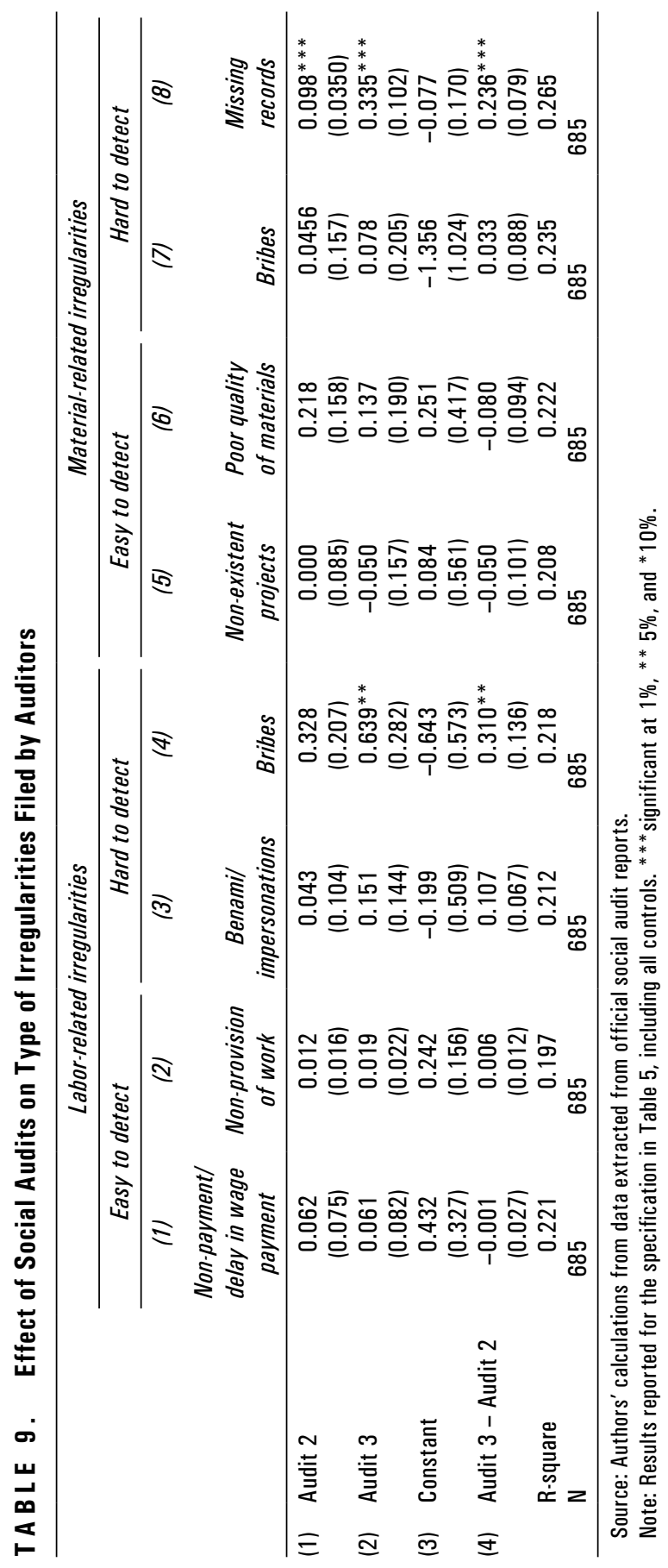




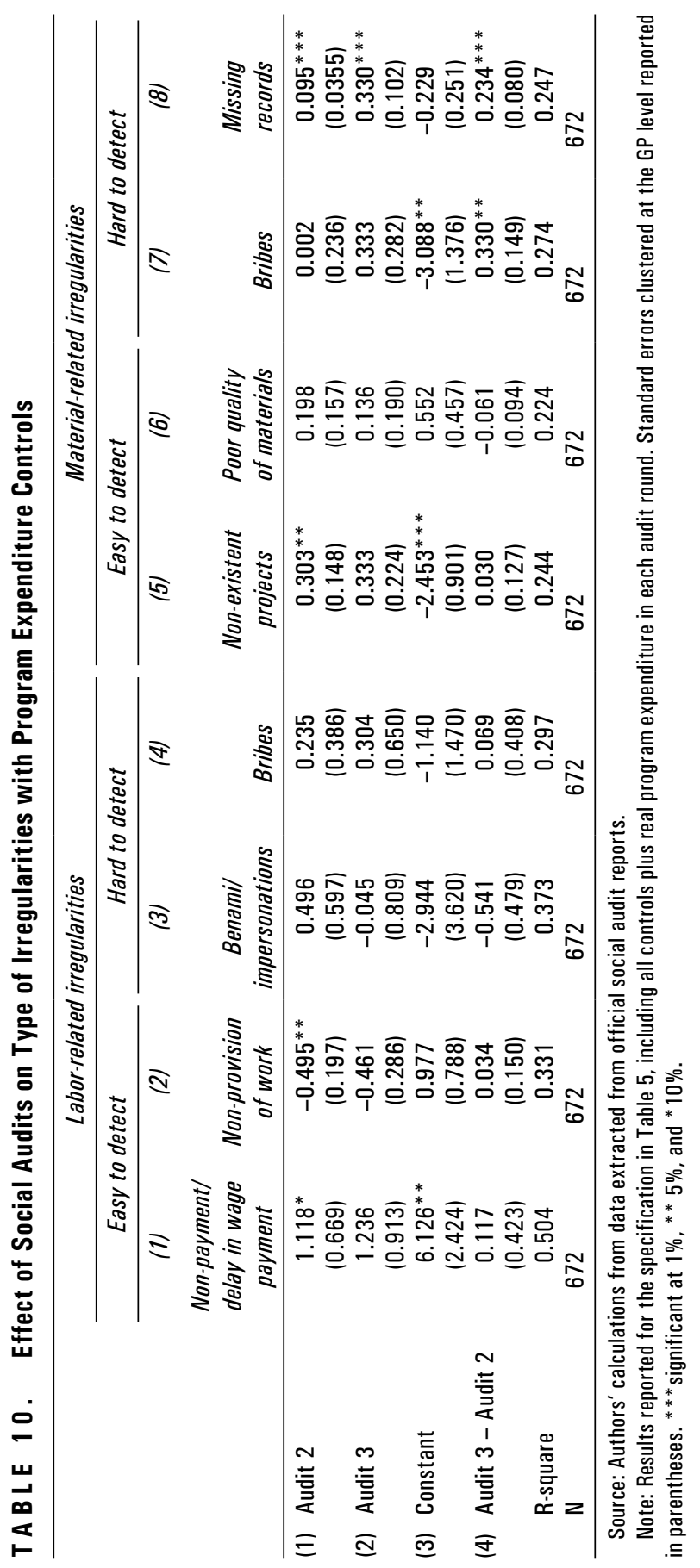




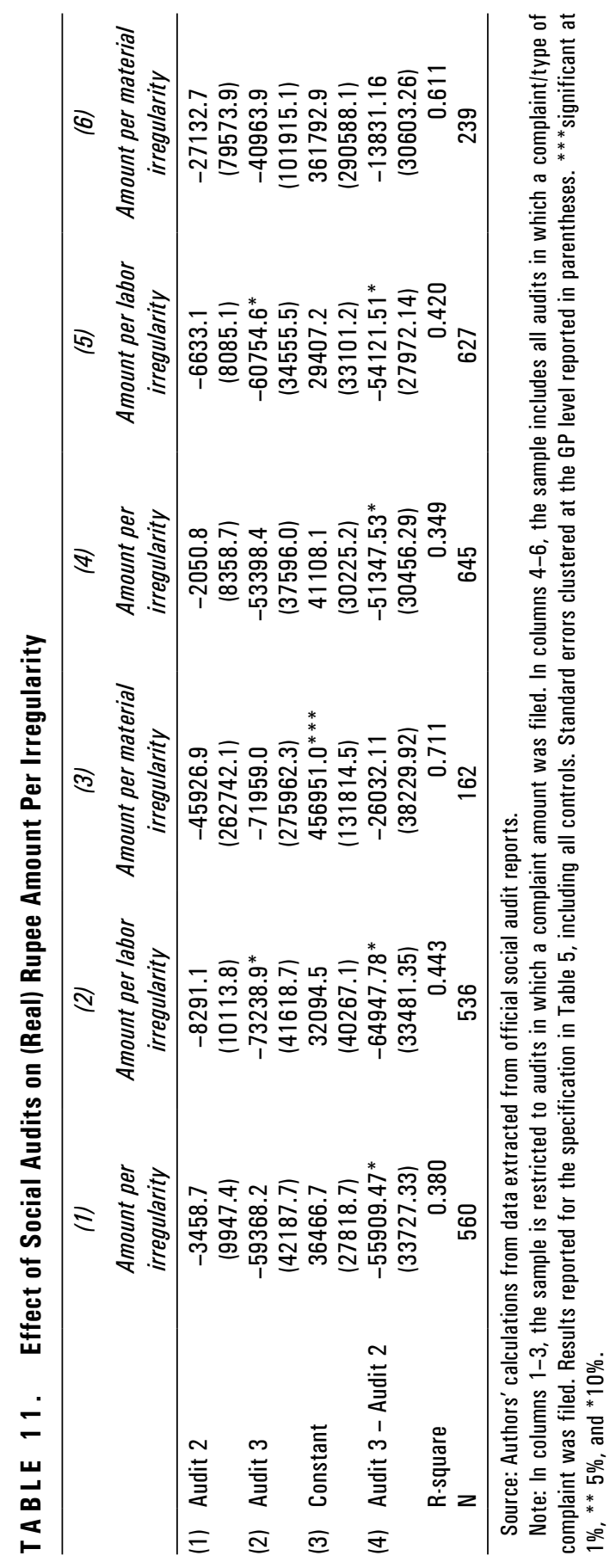


the dependent variable now representing the rupee amount per complaint (in 2006 rupees). The first three columns are restricted to audits where a complaint amount was mentioned while the next three columns are restricted to audits where any complaint was filed. If no amount was mentioned in the complaint, the amount per complaint is coded as zero. Missing amounts are more likely for complaints related to non-provision of work or wage payment delays. Across both definitions of the dependent variable, we find that the amount per complaint declined between the second and third audits for total complaints and labor complaints (row 4-columns 1, 2 and 4, 5) while there is no difference in the material complaint amounts (row 4-columns 3 and 6). This again suggests that the social audits may have had only a marginal impact on labor-related irregularities but have made little difference on the material front. ${ }^{29}$

\subsection{Heterogeneity}

In this section, we discuss whether and how the quality of MGNREGA implementation is associated with mandal-level characteristics. In the mandal survey, we interviewed current MPDOs. However, in several mandals MPDOs were transferred frequently. Frequent transfers of MPDOs could indicate political interference-either in response to irregularities in program implementation or, alternatively, be the cause of such irregularities. Note that we do not find a correlation between the number of irregularities in an audit for which the MPDO has been held responsible and the number of MPDOs posted in that mandal since 2006. We next split the sample by those mandals with less than median MPDO transfers (in our sample of 100 mandals the median number of MPDOs in each mandal since 2006 was 2, excluding the current MPDO) and those with higher than median transfers. The results are reported in Table 12 .

The top panel in Table 12 reports the results for less than median transfers of MPDOs. We find a significant decline in non-provision of MGNREGA work (column 4 ) in both audits 2 and 3 relative to audit 1 . Overall, there was a marginal increase in missing material expenditure records between audits 2 and 3 (column 11) but no overall change in the number of laboror material-related irregularities between audits 2 and 3 (columns 2 and 7, respectively).

In contrast, the bottom panel regressions for higher than median MPDO transfers suggest a significant and monotonic increase in the number of

29. A caveat to the results reported in Table 11 is potential selection bias: data on amounts are available only if an amount was mentioned in the complaint. 


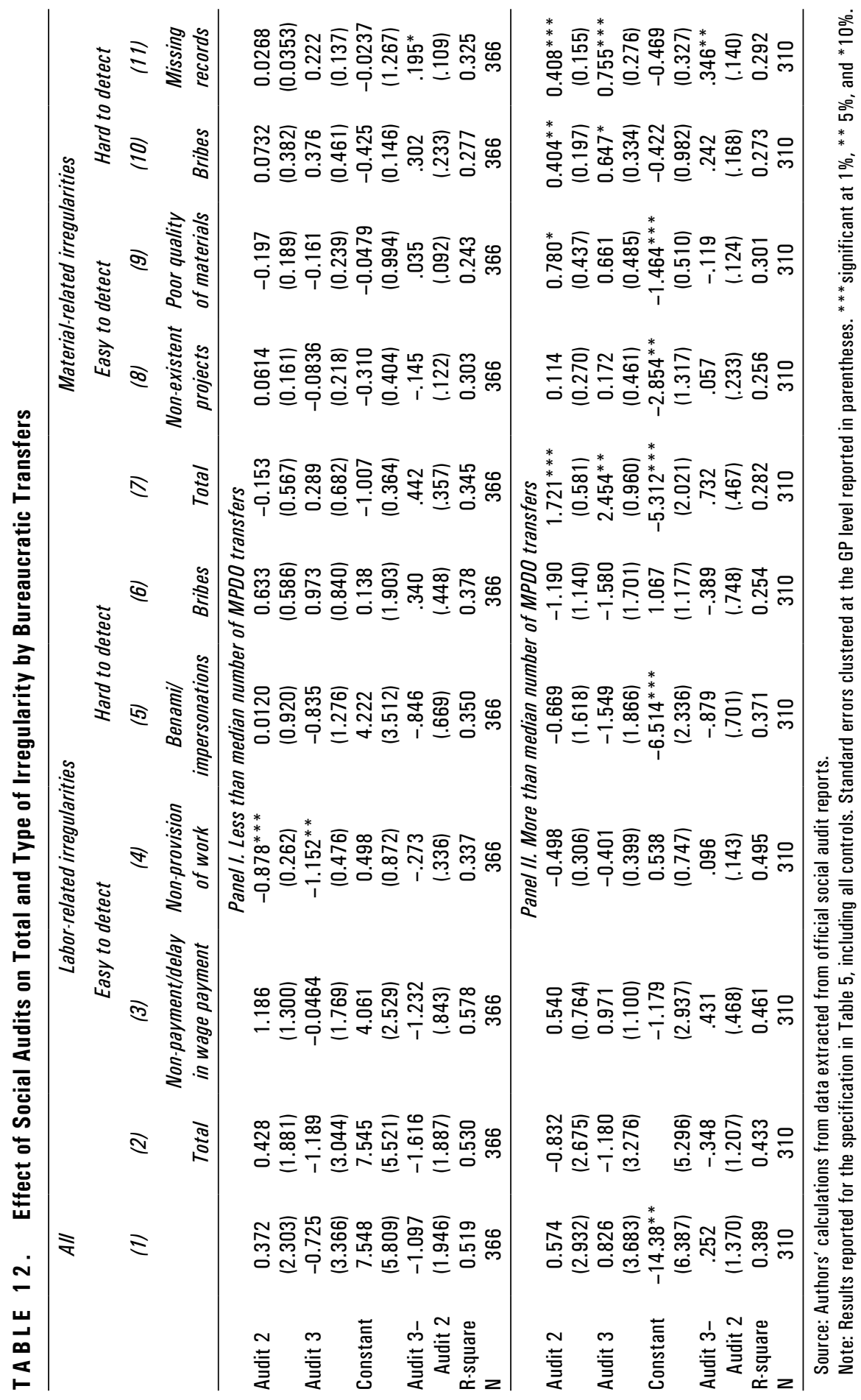


material-related irregularities relative to audit 1 (column 7). This was driven by an increase in material-related bribes (column 10) and missing expenditure records (column 11) in audits 2 and 3 relative to audit 1 . Thus, it is apparent that the results on material expenditures presented earlier for the entire sample are driven by mandals with frequent MPDO transfers. If transfers were in response to irregularities, then there should have been a declining trend in the number of irregularities in these mandals. On the contrary, the number of material-related irregularities rose consistently within these mandals. This suggests that transfers of bureaucrats could be an instrument used by the political class to influence the delivery of MGNREGA at the local level.

\section{Policy Implications and Concluding Remarks}

The AP social audit model is being scaled up and adopted by other Indian states and other public programs. In the introduction, we briefly reviewed what evidence tells us about the potential of participatory monitoring of the type the AP model has been developed around. Our first observation, which simply borrows Mansuri and Rao's (2013) conclusion, is that effective induced participation is difficult to achieve. At the same time, carefully crafted participatory interventions may (dramatically) improve (health) service delivery (BS 2009). Given the many similarities between BS's (2009) intervention and AP's social audits, there are thus grounds for optimism on behalf of the AP model. The zero impact of community mobilization and information sharing on teaching quality and learning outcomes in UP, reported by Banerjee et al. (2010), offers an important and sobering caveat. As our empirical results demonstrate, in relying on participation and social accountability, it is necessary to tread carefully and recognize potential pitfalls. Detection of audit "impacts" is made harder both by the fact that social audits were not implemented randomly and by the type of information (complaints) recorded by the social audit team. We, therefore, analyze the marginal impact of repeated audits within the same GPs during 2006-10. Controlling mandal-level attributes, overall and district-level time trends to address the confounders discussed earlier, we observe a marginal reduction in the real amount per labor complaint but an insignificant effect of the repeated social audit process on reducing the aggregate number of complaints. This is accompanied by an overall increase in the aggregate number of harderto-detect material-related irregularities over successive audit rounds with no change in the number of ETD irregularities. 
Based on our behavioral assumptions, we expected a decline in the ETD irregularities in which beneficiaries have high stakes and audit teams, as well as beneficiaries, have sufficient detection capacity. Although there is some indication of an overall decline in the amount of theft in labor-related irregularities, we do not observe a decline in any ETD labor- or materialrelated irregularities with successive audit rounds. ${ }^{30}$ Given our results, we can claim that while the top-down and participatory elements of the audit process have been effective in detecting irregularities, the audits are not an effective deterrent and have thus been unable to reduce irregularities.

Any marginal decline in the amount per labor-related administrative irregularity is, moreover, outweighed by the accompanying increase in the number of material-related complaints. We have seen that the complaints submitted by beneficiaries become increasingly sophisticated while the audit team complaints remain mostly confined to HTD irregularities. Given that we control time trends, we interpret the observed shift in the pattern of irregularities as reflective of transgressors responding to a new monitoring regime and the need to stay one step ahead of this monitoring regime. The threat of punishment may not have been credible for higher level program functionaries who are likely to be responsible (as much as, if not more than, lower level functionaries) for HTD, material-related malfeasance.

Note that the majority of labor-related irregularities were pinned on a GP-level, contractual functionary - the field assistant—who is typically a GP resident. The "naming and shaming" element of the public hearings might have been an effective deterrent for this particular functionary. However, social sanctions are unlikely to have a significant impact on curtailing malpractice among higher level program functionaries who are typically non-residents of the GP, such as the MPDO.

These results take us back to BS (2009) and to the social contract that their participatory process culminates in. We refer to this as the tightness of the social audit process. In spite of the promising prospects for communitybased monitoring of work provision and of labor-related expenditures, for the years that we have studied (2006-10), the follow up and enforcement of social audit findings in AP were weak: this may contribute to explain the limited success of the social audit process in deterring malfeasance. As shown in Table 13, while this weakness may have been mitigated by the

30. During the period of our study the state introduced significant technological innovations in the monitoring and processing of labor payments. A centralized computer system where muster-rolls are verified and payments made on a weekly basis through computer generated pay orders at the mandal level may, alongside the audits, have helped to mitigate leakages in labor payments. 


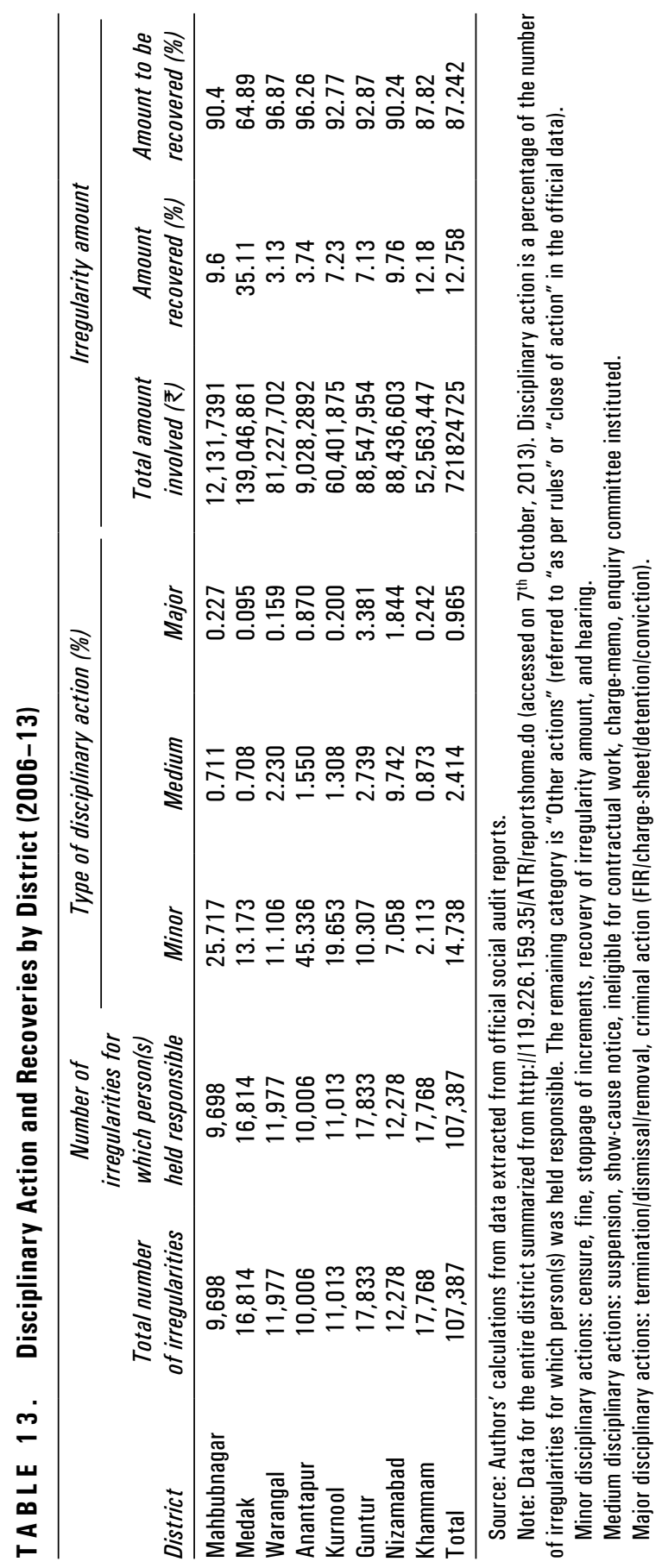


establishment of the vigilance cells in AP in 2010, less than $1 \%$ of irregularities for which one or multiple program functionaries were held responsible ended in termination/dismissal/removal from service or criminal action for the period under study (and until 2013). Furthermore, $87 \%$ of the missing amounts were yet to be recovered. The effectiveness of social audits in deterring theft and other malpractice, in spite of all their other inherent merits, may thus be undermined by a single design weakness, or slip-up. A key lesson for AP and for states emulating the AP model would thus be to ensure that social audits culminate in the type of enforceable and credible "contract" that allocates responsibilities, defines timelines, and ensures that those who have been found guilty of irregularities are promptly punished. The credibility of the social audit process rests ultimately on the ability and willingness of the state government to take effective remedial action and punish offenders.

In principle, the modest impact of social audits could also reflect a problem of capacity on the part of social audit teams. In our discussions earlier, we assume that as the social audit process is repeated, core social audit personnel learn and amass new knowledge and understanding. This should make audits increasingly effective and auditors more able to detect more sophisticated irregularities. This conjecture is only plausible if core personnel stays put or learning is effectively transferred to new staff. ${ }^{31}$

Apart from the results outlined earlier, our work here underlines the need for incorporating rigorous program evaluation in the roll out of audits. Furthermore, greater vigilance in the documentation of social audit evidence, which could be critical for assessing the impact of these audits, is essential. For instance, all social audit reports include questions on the total rupee amount of irregularities, the total amount of MGNREGA expenditures subjected to audit, etc., to be filled in by the audit team. But these data are not entered in the vast majority of social audit reports for the period and sample under study. Careful documentation of audit findings would, again, require improvements in the training of auditors and greater emphasis on the importance of more complete documentation in the training modules.

The AP experience has uniquely benefitted from the top level and strong political commitment to the social audit process. The state has also demonstrated a strong willingness to experiment with the use of technology and

31. Experience-based skill accumulation may become obsolete if the portfolio of MGNREGA projects undergoes significant change. This is an issue other adopting states need to pay attention to. Intensification of scrutiny may shift priorities toward projects with more material expenditure and harder to detect irregularities. 
other mechanisms to strengthen monitoring and the quality of MGNREGA delivery (Murali 2013). These favorable initial conditions have, no doubt, critically aided and bolstered the potential of the social audit process in AP. A key question is whether similar preconditions are likely to be present in the other states that are now seeking to replicate the AP model. Our study underlines the advantages of a top-down component in designing social audits to leverage grassroots participation.

Following the transition from the work fare programs prior to the rightsbased MGNREGA, between 2004-05 and 2008-09 there has been a threefold increase in Central government funds allocated to rural work projects (Afridi 2008). In 2011-12, the Act had provided employment to almost 40 million households at an annual expenditure of almost ₹40,000 crores across the country while the cost of conducting these audits is merely $1 \%$ of this expenditure. The potential benefits of the program are large but the cost of making certain that they are realized is low. In moving forward, we reiterate the high stakes in ensuring the success of the social audit mechanism.

\section{Appendix}

T A B L E A 1. Number of Irregularities Per District Per Audit

\begin{tabular}{lcccccccc}
\hline & Mahbub- & \multicolumn{3}{c}{ Ananta- } & \multicolumn{3}{c}{ Nizama- } \\
Audit\# & nagar & Medak & Warangal & pur & Kurnool & Guntur & bad & Khammam \\
\hline \multirow{4}{*}{ Audit1 } & {$[\mathrm{N}=36]$} & {$[\mathrm{N}=37]$} & {$[\mathrm{N}=41]$} & {$[\mathrm{N}=36]$} & {$[\mathrm{N}=33]$} & {$[\mathrm{N}=33]$} & {$[\mathrm{N}=36]$} & {$[\mathrm{N}=32]$} \\
& 4.972 & 3.297 & 4.317 & 6.111 & 5.121 & 2.090 & 4.972 & 10.625 \\
& $(3.714)$ & $(2.259)$ & $(2.240)$ & $(3.970)$ & $(3.621)$ & $(2.517)$ & $(3.009)$ & $(6.791)$ \\
& {$[\mathrm{N}=36]$} & {$[\mathrm{N}=33]$} & {$[\mathrm{N}=39]$} & {$[\mathrm{N}=36]$} & {$[\mathrm{N}=33]$} & {$[\mathrm{N}=12]$} & {$[\mathrm{N}=36]$} & {$[\mathrm{N}=36]$} \\
Audit2 & 7.333 & 5.181 & 6.949 & 4.389 & 5.848 & 2.833 & 5.167 & 9.833 \\
& $(4.296)$ & $(3.486)$ & $(5.370)$ & $(3.728)$ & $(6.251)$ & $(1.850)$ & $(4.532)$ & $(7.588)$ \\
& {$[\mathrm{N}=6]$} & {$[\mathrm{N}=36]$} & {$[\mathrm{N}=42]$} & {$[\mathrm{N}=14]$} & {$[\mathrm{N}=9]$} & & {$[\mathrm{N}=32]$} & {$[\mathrm{N}=27]$} \\
Audit3 & 6.667 & 5.611 & 8.405 & 2.214 & 3.444 & & 7.75 & 5.518 \\
& $(3.502)$ & $(7.184)$ & $(7.960)$ & $(2.326)$ & $(2.297)$ & & $(6.289)$ & $(4.577)$ \\
\hline
\end{tabular}

Source: Authors' calculations from data extracted from official social audit reports. Note: Number of observations in square brackets. Standard errors in parentheses.

\section{References}

Aakella, K. V. and S. Kidambi. 2007. "Social Audits in Andhra Pradesh: A Process in Evolution," Economic and Political Weekly, 42 (47): 18-19.

Adato, M., J. Hoddinott, and L. Haddad. 2005. "Power, Politics and Performance: Participation in South African Public Work Programs," Research Report 143, International Food Policy Research Institute, Washington, D.C. 
Afridi, F. 2008. "Can Community Monitoring Improve the Accountability of Public Officials?” Economic and Political Weekly, Mumbai, 43 (42): 35-40.

Aiyar, Y., S. K. Mehta, and S. Samji. 2013. "India: Implementing Social Audits," in K. Subbarao et al. 2013. Chapter 11, pp. 249-68.

Banerjee, A. V., R. Banerji, E. Duflo, R. Glennester, and S. Khemani. 2010. "Pitfalls of Participatory Programs: Evidence from a Randomized Evaluation in Education in India," American Economic Journal: Economic Policy, 2(1): 1-30.

Bjorkman, M. and J. Svensson. 2009. "Power to the People: Evidence from a Randomized Experiment on Community Based Monitoring in Uganda," Quarterly Journal of Economics, 124 (2): 735-69.

Deshingkhar, P. and C. Johnson. 2003. State Transfers to the Poor and Back: The Case of the Food for Work Programme in Andhra Pradesh. Working Paper 222, Overseas Development Institute, London.

Government of India. 2005. Mahatma Gandhi National Rural Employment Guarantee Act. Available at http://www.rural.nic.in/sites/programmes-schemesMGNREGA.asp (accessed on May 20, 2014).

Joshi, A. and P. Houtzager. 2012. "Widgets or Watchdogs? Conceptual Explorations in Social Accountability," Public Management Review, 14 (2): 145-62.

Khemani, S. 2008. "Does Community Monitoring Improve Public Services? Based on Evidence from Uganda and India the answer is 'Yes' and 'No'," World Bank Research Brief, September.

Mansuri, G and V. Rao. 2013. Localizing Development - Does Participation Work? Washington, D.C.: The World Bank.

Murali, A. 2013. India: Technological Innovation for Effective Management Information Systems, in K. Subbarao et al. 2013. Chapter 10, pp. 233-48.

Olken, Ben. 2009. "Corruption Perceptions vs. Corruption Reality," Journal of Public Economics, 93 (7-8): 950-964.

Olken, Ben and Rohini Pande. 2011. "Corruption in Developing Countries," NBER Working Paper No. 17398.

Ringold, D., A. Holla, M. Koziol, and S. Srinivasan. 2012. Citizens and Service Delivery-Assessing the Use of Social Accountability Approaches in Human Development. Washington, D.C.: The World Bank.

Subbarao, K., C. del Ninno, C. Andrews, and C. Rodriguez-Alas. 2013. Public Works as a Safety Net: Design, Evidence and Implementation. Washington, D.C.: The World Bank.

World Bank. 2011. Curbing Fraud, Corruption and Collusion in the Roads Sector. Washington, D.C.: The World Bank. 